\title{
Effect of freezing period and defrosting methods on chemical composition and microbial count in beef cuts
}

\author{
RC Biswas* ${ }^{1}$, S Akhter ${ }^{1}$, MM Hossain $^{1}$, MS Rana², M Habibullah $^{1}$ \\ ${ }^{1}$ Department of Animal Science, Bangladesh Agricultural University, Mymensingh 2202,; ${ }^{2}$ Bangladesh Livestock \\ Research Institute, Savar, Dhaka, Bangladesh
}

\begin{abstract}
The experiment was conducted to examine the effect of freezing and defrosting methods on the quality of beef. Two types of beef samples named as fresh and cured beef samples were taken. Both types were divided into three sub divisions namely air, water and microwave oven. These samples were stored at $-20^{\circ} \mathrm{C}$ temperature in the freezer for 90 days and analyzed on $10^{\text {th }}, 45^{\text {th }}$ and $90^{\text {th }}$ day. The dry matter, crude protein, ether extract and ash percentages and standard plate count (SPC) were differed significantly $(p<0.01)$ among the air, water and microwave defrosted samples. Up to $90^{\text {th }}$ days of freezing at $-20^{\circ} \mathrm{C}$ dry matter content increased with the increase of storage time almost in all samples except microwave fresh samples. The protein content decreased with the increase of storage time from 10 to 45 days but increased from 45 to 90 days. The ash content decreased with the increase of storage time in case of fresh frozen samples but increased with the increase of storage time in case of cured frozen samples except microwave oven cured sample. Ether extract value gradually increased with the increasing of storage period in case of air fresh, water fresh, air cured and water cured frozen samples but decreased with the increasing of storage period in case of microwave oven fresh and microwave oven cured samples. The SPC value increased with the increase of storage time in case of all samples and differed significantly $(p<0.01)$ among the parameters. The cured microwave defrosted beef was proved as the best technique of defrosting frozen beef.
\end{abstract}

Key words: Preservation, storage time, beef, quality

Bangladesh Animal Husbandry Association. All rights reserved. Bang. J. Anim. Sci. 2014.43 (3): $202-206$

\section{Introduction}

Animal protein is one of the most essential nutrient for human. Meat contains all the essential amino acids required for human body. The total requirement of meat in our country is 6.30 million tons, while the production is 1.10 million tons with a deficit of 5.20 million tons (BBS 2009). The per capita requirement and availability of meat per day in the country are $120 \mathrm{~g}$ and $24.38 \mathrm{~g}$, respectively (DLS 2012). Out of total meat production, $51.92 \%$ come from cattle, $1.92 \%$ from buffalo, $7.69 \%$ from goat, $0.96 \%$ from sheep and $32.69 \%$ from chicken and $4.81 \%$ from duck (DLS 2009). Most of the cattle are being slaughtered every year in Bangladesh during a single occasion like Eid-Ul-Azha. Unfortunately, there is no suitable techniques of meat preservation in the country. During Eid-UIAzha in some rural areas of country, meats are being preserved by drying method for home consumption.
In a broad sense, preservation of meat is the prevention in changes in flavor, odor, texture, appearance, nutritive contents and other factors, which are associated with the quality of the product. As a matter of fact, meat preservation is the controlling of putrefactive bacterial action. Different preservation methods of meat have been developed. Among them freezing is one of the most effective techniques for long time preservation in our country. Freezing is the only known technique by which meat and meat products can be preserved in a condition similar to that of normal state and can be kept satisfactorily for six months to one year (Sebranek et al. 1979). Fresh meat contains almost same food value and flavor after freezing. During Eid-ul-Azha, the surplus meat is preserved by freezing in urban areas. There is no definite information on effect of different preservation techniques and storage time for beef and their chemical and microbial changes. Thus, the present study was undertaken to investigate the 
effect of different preservation techniques and storage time on beef composition and microbial changes.

\section{Materials and Methods}

Boneless beef cuts from freshly slaughtered cattle were purchased from a market at 8.00 AM. The meat sample was immediately transferred to the Animal Science Laboratory, Bangladesh Agricultural University, Mymensingh. All the necessary instruments were cleaned and then dried properly before starting the experimental activities. Visible fats and connective tissues were trimmed off with the help of a knife and the sample was cut into small pieces ( $2 \mathrm{~g} /$ piece). Beef was divided into two portion of which one was mixed with spices viz chili powder, turmeric powder and salts to maintain keeping quality through curing and then divided into 4 parts. Another portion of fresh sample was also divided into 4 parts. The samples were packaged $(10 \mathrm{~g} /$ pack) in poly-ethylene bags separately. Then it was kept in two different freezes at $-5{ }^{\circ} \mathrm{C}$ and $-20{ }^{\circ} \mathrm{C}$, respectively. Samples stored at $-5^{\circ} \mathrm{C}$ named refrigerated and samples stored at $-20^{\circ} \mathrm{C}$ named frozen beef.

Proximate composition such as dry matter (DM), crude protein $(C P)$, ether extract (EE) and ash of the samples were determined according to the methods (AOAC 2005). All determinations were done in triplicate and the mean value was recorded. The $\mathrm{pH}$ value of meat sample was measured using a $\mathrm{pH}$ meter from meat homogenate. The homogenate was prepared by blending $2 \mathrm{~g}$ of meat with $10 \mathrm{ml}$ distilled water.

Standard plate count (SPC) technique was used to assess microbial concentration. All the petri dishes and bottles were sterilized and dried properly. Two gram meat sample was grounded, out of it $1 \mathrm{~g}$ sample was dipped into alcohol, soaked with white paper and then sample was poured into the prepared buffer solution. The sample was mixed with hand shaking. Then 2.1 $\mathrm{ml}$ mix was poured into two petri dishes: $0.1 \mathrm{ml}$ and $1.0 \mathrm{ml}$ respectively and rest of the mix was poured into the buffer solution and mixed properly. This process was repeated three times until ready to 8 dilutions. The agar solution was poured into the petri dishes. The petri dishes were stored in incubator at $32{ }^{\circ} \mathrm{C}$ for 48 hours.
After 48 hours colony were counted by colony counter.

The data were analyzed statistically using the analysis of variance technique in a computer using SAS statistical computer package programmed in accordance with the principle of factorial block design. Duncan's multiple range test was done to compare variations between treatments.

\section{Results and Discussion}

Table 1 shows DM, CP, EE, ash and SPC of the sample $M_{1}, M_{2}, M_{3}, M_{4}, M_{5}$, and $M_{6}$ in beef. The Table reveals that the DM, CP, EE and Ash percentage and SPC of the sample $M_{1}, M_{2}, M_{3}$, $M_{4}, M_{5}$, and $M_{6}$ differed significantly $(p<0.01)$. The DM percentage was significantly $(p<0.01)$ higher in sample $M_{5}$ and lower in sample $M_{1}$ and $M_{2}$ but there was no significant difference between $M_{1}$ and $M_{2}$ and between $M_{4}$ and $M_{6}$. The $C P$ percentage was significantly $(p<0.01)$ higher in sample $M_{3}$ and lower in sample $M_{1}$ but there was no significant difference between $M_{2}$ and $M_{4}$. Ash percentage was significantly $(p<0.01)$ higher in sample $M_{5}$ and lower in sample $M_{1}$ and $M_{2}$ but there was no significant difference between $M_{1}$ and $M_{2}$. The $E E$ percentage was significantly $(p<0.01)$ higher in sample $M_{3}$ and $M_{6}$ and lower in sample $M_{2}$ but there was no significant difference between $M_{2}$ and $M_{3}$. SPC was significantly $(p<0.01)$ higher in sample $M_{3}$ and lower in sample $\mathrm{M}_{4}$.

Table 1. Effect of sample types on different parameters of frozen beef

\begin{tabular}{lcccccc}
\hline Parameters & $\mathrm{M}_{1}$ & $\mathrm{M}_{2}$ & $\mathrm{M}_{3}$ & $\mathrm{M}_{4}$ & $\mathrm{M}_{5}$ & $\mathrm{M}_{6}$ \\
\hline DM (\%) & $25.17^{\mathrm{d}}$ & $25.44^{\mathrm{d}}$ & $27.64^{\mathrm{c}}$ & $30.8 \mathrm{a}^{\mathrm{b}}$ & $32.03^{\mathrm{a}}$ & $29.45^{\mathrm{b}}$ \\
CP (\%) & $21.45^{\mathrm{c}}$ & $23.45^{\mathrm{b}}$ & $26.47^{\mathrm{a}}$ & $23.35^{\mathrm{b}}$ & $22.56^{\mathrm{bc}}$ & $25.52^{\mathrm{a}}$ \\
EE (\%) & $1.80^{\mathrm{c}}$ & $1.12^{\mathrm{d}}$ & $4.50^{\mathrm{a}}$ & $2.01^{\mathrm{c}}$ & $2.80^{\mathrm{b}}$ & $4.10^{\mathrm{a}}$ \\
Ash (\%) & $1.21^{\mathrm{c}}$ & $1.35^{\mathrm{c}}$ & $1.378^{\mathrm{c}}$ & $6.05^{\mathrm{b}}$ & $6.89^{\mathrm{a}}$ & $6.22^{\mathrm{ab}}$ \\
SPC (x106no.) & $52^{\mathrm{c}}$ & $68^{\mathrm{b}}$ & $128^{\mathrm{a}}$ & $40^{\mathrm{e}}$ & $48^{\mathrm{d}}$ & $50^{\mathrm{cd}}$ \\
\hline
\end{tabular}

Means with different superscript in the same raw differed significantly $(p<0.01) ; S P C$, standard plate count; $M_{1}$, air fresh frozen sample; $M_{2}$, water fresh frozen sample; $M_{3}$, microwave fresh frozen sample; $M_{4}$, air cured frozen sample; $M_{5}$, water cured frozen sample; $M_{6}$, microwave cured frozen sample

The effect of defrosting methods i.e. air, water and microwave oven on DM, CP, EE, ash and SPC is summarized in Table 2 . The results indicated 


\section{Chemical composition and microbial count in beef cuts}

that there were no significant differences ( $p>0.05)$ of air, water and microwave defrosted samples on DM, CP, Ash and EE of beef. However, the significant difference $(p<0.01)$ was found in SPC among different samples. Defrosting of frozen meat by air and water took 2 to 3 times more than the defrosting by microwave oven. For this reason, air and water defrosted samples lost more moisture than the microwave defrosted samples. The DM and ash content are higher in water defrosted samples which is consistent with the findings of Modak (2009). The SPC content in air defrosted samples $\left(92.5 \times 10^{6}\right.$ no. $)$ was significantly $(p<0.01)$ higher than that of microwave oven $\left(67.83 \times 10^{6}\right.$ no. $)$ and water $\left(64.16 \times 10^{6}\right.$ no. $)$ defrosted samples. But there was no significant difference between microwave and water defrosted samples. This indicated that microbial contamination was significantly lower $(p<0.01)$ at water and microwave oven defrosted samples due to minimum time of exposing in water for defrosting. The SPC content was in higher air that water defrosted samples which were similar to that of the result of Modak (2009).

Table 3 shows the interaction effect of different preservation techniques and storage time on DM, $\mathrm{CP}$, ash, EE and SPC content of frozen beef. There were significant differences $(p<0.01)$ of storage techniques on DM content of frozen beef when the samples were stored for 10, 45 and 90 days.

Table 2. Effect of defrosting methods on different parameters of frozen beef

\begin{tabular}{lccc}
\hline \multirow{2}{*}{ Parameters } & \multicolumn{3}{c}{ Defrosting methods } \\
\cline { 2 - 4 } & Air & Water & Oven \\
\hline DM (\%) & 29.35 & 31.55 & 29.05 \\
CP (\%) & 23.61 & 24.20 & 25.45 \\
EE (\%) & 5.31 & 7.23 & 5.56 \\
Ash (\%) & 1.39 & 1.46 & 1.36 \\
SPC (×106)(no.) & $92.5^{\mathrm{a}}$ & $64.16^{\mathrm{b}}$ & $67.83^{\mathrm{b}}$ \\
\hline
\end{tabular}

Means with different superscript in the same raw differed significantly $(p<0.01) ; S P C$, standard plate count

The DM content of frozen beef was significantly $(p<0.01)$ higher in water cured sample $(30.94 \%)$ and lower in air fresh sample $(24.02 \%)$ at 10 days storage time, higher in water cured samples $(32.34 \%)$ and lower in air fresh samples (28.34\%) at 45 days storage time and higher in air cured samples $(37.62 \%)$ and lower in microwave oven fresh samples $(28.54 \%)$ at 90 days storage time. The DM content increased with the increase of storage time almost in all samples except microwave oven fresh samples. The loss of moisture probably associated with increased DM.

Table 3. Interaction effect of different defrosting method and storage time on frozen beef

\begin{tabular}{|c|c|c|c|c|c|c|c|}
\hline \multirow{2}{*}{$\begin{array}{l}\text { Parameters } \\
\text { (DM Basis) }\end{array}$} & \multirow{2}{*}{$\begin{array}{l}\text { Storage time } \\
\quad \text { (days) }\end{array}$} & \multicolumn{3}{|c|}{ Fresh frozen } & \multicolumn{3}{|c|}{ Cured frozen } \\
\hline & & Air fresh & Water fresh & Microwave fresh & Air cured & Water cured & Microwave cured \\
\hline \multirow{3}{*}{ DM (\%) } & 10 & $24.02^{e}$ & $28.02^{b}$ & $27.93^{b}$ & $27.17 c$ & $30.94 a$ & $25.85^{d}$ \\
\hline & 45 & $28.34^{d}$ & $30.76^{b}$ & $29.46^{c}$ & $29.58^{c}$ & $32.34^{a}$ & $30.87^{b}$ \\
\hline & 90 & $29.42^{d}$ & $32.26^{c}$ & $28.54 \mathrm{e}$ & $37.62^{\mathrm{a}}$ & $35.00^{b}$ & $31.66^{c}$ \\
\hline \multirow{3}{*}{$\mathrm{CP}(\%)$} & 10 & $24.95^{b}$ & $26.13^{a}$ & $26.83^{a}$ & $24.48^{b}$ & $27.29 a$ & $26.64^{a}$ \\
\hline & 45 & $21.84^{b}$ & $20.18^{c}$ & $23.50^{\mathrm{a}}$ & $19.39 \mathrm{~cd}$ & $17.82^{\mathrm{e}}$ & $19.04^{d}$ \\
\hline & 90 & $25.64^{d}$ & $27.34^{b}$ & $28.17^{a}$ & $25.36^{d}$ & $26.47 c$ & $28.54^{a}$ \\
\hline \multirow{3}{*}{$\mathrm{EE}(\%)$} & 10 & $5.50^{d}$ & $5.50^{\mathrm{a}}$ & $5.50^{d}$ & $5.20^{d}$ & $8.60^{b}$ & $7.80^{\circ}$ \\
\hline & 45 & $3.5 \mathrm{de}$ & $4.30^{a}$ & $3.19 \mathrm{e}$ & $5.09 c$ & $7.50^{\mathrm{b}}$ & $6.85^{d}$ \\
\hline & 90 & $6.00^{c}$ & $7.80^{\mathrm{b}}$ & $4.42^{\mathrm{d}}$ & $6.80^{c}$ & $9.70^{a}$ & $5.64 \mathrm{e}$ \\
\hline \multirow{3}{*}{ Ash (\%) } & 10 & $1.49^{b}$ & $1.74^{\mathrm{a}}$ & $1.32^{\mathrm{bc}}$ & $1.07^{d}$ & $1.23^{\text {cd }}$ & $1.42^{b c}$ \\
\hline & 45 & $1.54^{\text {ab }}$ & $1.67^{a}$ & $1.42^{b c}$ & $1.38^{\mathrm{bc}}$ & $1.28^{c}$ & $1.54^{\mathrm{ab}}$ \\
\hline & 90 & $1.42^{\mathrm{a}}$ & $1.56^{\mathrm{a}}$ & $1.36^{\mathrm{ab}}$ & $1.44^{a}$ & $1.33^{\mathrm{ab}}$ & $1.11^{\mathrm{b}}$ \\
\hline \multirow{3}{*}{ SPC $\left(x 10^{6}\right)($ no. $)$} & 10 & $85^{b}$ & $56^{d}$ & $65 c$ & $90 \mathrm{a}$ & 50 & $45^{\dagger}$ \\
\hline & 45 & $89 \mathrm{~b}$ & $65^{c}$ & $86^{b}$ & $94^{a}$ & $60^{d}$ & $48 \mathrm{e}$ \\
\hline & 90 & $98^{a}$ & $82^{c}$ & $97^{b}$ & $99 a$ & $72^{d}$ & $66^{\mathrm{e}}$ \\
\hline
\end{tabular}

Means with different superscript in the same raw differed significantly $(p<0.01)$; SPC, standard plate count 

The same trend was also observed by Konieczny et al. (2007) and Modak (2009). They reported that DM content increased during frozen storage. Kondaiah et al. (1986) investigated decreasing trend on the moisture content with the storage of time. The marked moisture losses encountered in later storage periods may be accounted for the myofibrillar distortion undergone by the meat in the freezer that led to the poor water retention ability of the meat.

The results indicated that there were significant differences of storage techniques on $\mathrm{CP}$ content of frozen beef when the samples were stored for 10 days $(p<0.05), 45$ days $(p<0.01)$ and 90 days $(p<0.05)$. The CP content of frozen beef was significantly $(p<0.05)$ higher in water cured samples $(27.29 \%)$ and lower in air cured samples $(24.48 \%)$ )at 10 days storage time, significantly $(p<0.01)$ higher in microwave oven fresh samples $(23.50 \%)$ and lower in water cured samples $(17.82 \%)$ at 45 days storage time and significantly $(p<0.05)$ higher in microwave oven cured sample $(28.54 \%)$ and lower in air cured samples $(25.36 \%)$ at 90 days storage time. The protein content decreased with the increase of storage time (from 10 days to 45 days) but increased from 45 days to 90 days of storage time.

The loss of protein during storage in those samples may be related with loss of sarcoplasmic protein probably due to the osmosis and poor water holding capacity. Sarcoplasmic protein (water soluble protein) may be lost during frozen storage in the form of drip loss. Faisal et al. (2009) and Konieczny et al. (2007) investigated that protein content of beef decreased during frozen storage and Modak (2009) investigated that protein content of beef increased during frozen storage. Myofibrillar protein solubilities decreased with storage time (Farouk et al. 2004) and decrease in solubility is an indication of denaturation of proteins (Miller et al. 1980; Sebranek et al. 1979; Shenouda 1980), which is responsible for the loss of quality with time.

There were significant differences $(p<0.01)$ of storage techniques on EE content of frozen beef when the samples were stored for 10 days, 45 days and 90 days. The EE content of frozen beef was significantly $(p<0.01)$ higher in water fresh samples $(5.50 \%)$ and lower in air cured samples
(5.20\%) at 10 days storage time, higher in water fresh sample $(4.30 \%)$ and lower in microwave oven fresh samples (3.19\%) at 45 days storage time and higher in water cured samples $(9.70 \%)$ and lower in microwave oven cured samples $(5.64 \%)$ at 90 days storage time. EE value gradually increased with the increasing of storage period in case of air fresh, water fresh, air cured and water cure samples but decreased with the increasing of storage period in case of microwave oven fresh and microwave oven cured samples. Modak (2009) investigated that fat content of beef increased during frozen storage.

There were significant differences $(p<0.01)$ of storage techniques on ash content of frozen beef when the samples were stored for 10 days, 45 days and 90 days. The ash content of frozen beef was significantly $(p<0.01)$ higher in water fresh samples $(1.74 \%)$ and lower in air cured samples $(1.07 \%)$ at 10 days storage time, higher in water fresh samples $(1.67 \%)$ and lower in water cured samples $(1.28 \%)$ at 45 days storage time and higher in water fresh samples ( $1.56 \%)$ and lower in microwave oven cured samples $(1.11 \%)$ at 90 days storage time. The ash content decreased with the increase of storage time in case of fresh frozen samples but increased with the increase of storage time in case of cured frozen samples except microwave oven cured sample. In fact, Kandeepan (2006) showed decreasing trend in ash content with storage of time.

There were significant differences $(p<0.01)$ of storage techniques on SPC count of frozen beef when the samples were stored for 10 days, 45 days and 90 days. The SPC count frozen beef was significantly $(p<0.01)$ higher in air cured sample $\left(90 \times 10^{6}\right.$ no. $)$ and lower in microwave oven cured samples $\left(45 \times 10^{6}\right.$ no. $)$ at 10 days storage time, higher in air cured sample $\left(94 \times 10^{6}\right.$ no. $)$ and lower in microwave oven cured samples $\left(48 \times 10^{6}\right.$ no.) at 45 days storage time and higher in air cured samples $\left(99 \times 10^{6}\right.$ no. $)$ and lower in microwave oven cured samples $\left(66 \times 10^{6}\right.$ no. $)$ at 90 days storage time. SPC value increased with the increase of storage time in case of all samples which was supported by Modak (2009).

\section{Conclusion}

It is revealed from the above findings that micro wave oven cured frozen beef can be the suitable 
Biswas et al. (2014) Bang. J. Anim. Sci. 43 (3): 202- 206

method because of lower change of nutrients and lower microbial count. It is also recommended that water can be used for defrosting beef cuts in places where microwave is not available.

\section{References}

AOAC (Association of Official Analytical Chemists) (2005). Official Methods of Analysis, Association of Official Analytical Chemists. $13^{\text {th }}$ Ed., Washington, DC, P. 957.

BBS (2009). Bangladesh Bureau of Statistics, Statistics Division, Ministry of Planning, Government of the Peoples Republic of Bangladesh, Dhaka.

DLS (Department of Livestock Services) (2012). Ministry of Fisheries and Livestock, Statistical Yearbook of Bangladesh, 201112.

DLS (Department of Livestock Services) (2009). Ministry of Fisheries and Livestock, Personal Communication.

Faisal SB, Akhter S, Hossain MM (2009). Effect of different methods of preservation on the quality of cattle and goat meat. Bangladesh Journal of Animal Science, 38: 86 - 91.

Farouk MM, Wieliczko KJ, Merts I (2004). Ultrafast freezing and low storage temperatures are not necessary to maintain the functional properties of manufacturing beef. Journal of Meat Science, 66: 171179.

Kandeepan (2006). Effect of low temperature preservation on quality and shelf life of buffalo meat. Division of Livestock Products
Technology, Indian Veterinary Research Institute, I zatnagar, India.

Kondaiah N, Anjaneyulu ASR, Kesava Rao V, Sharma $N$ (1986). Effect of different handling conditions on quality of minced buffalo meat. Indian Journal of Animal Science, 56: 677-679.

Konieczny P, Stangierski J, Kijowski, J (2007). Physical and chemical characteristics and acceptability of home style beef jerky. Meat Science, 76: 253-257.

Miller AJ, Ackerman SA, Palumbo SA (1980). Effects of frozen storage on functionality of meat for further processing. Journal of Food Science, 45: 1466-1471.

Modak AK (2009). Effect of freezing temperature and defrosting methods on the quality of beef. MS Thesis. Department of Animal Science, Bangladesh Agricultural University, Mymensingh 2202.

Sebranek JG, Sang PN, Topel DG, Rust RE (1979). Effects of freezing methods and frozen storage on chemical characteristics of ground beef patties. Journal of Animal Science, 4: 1101-1108.

Shenouda SYK (1980). Theories of protein denaturation during frozen storage of fish flesh. Advances in Food Research, 26: 275-311.

Tailor AA, Down NF, Shaw BG (1990). A comparison of modified atmosphere and vacuum skin packing for the storage of red meats. International J ournal of Food Sciene and Technology, 25: 98-109. 